\title{
PERANCANGAN SISTEM INFORMASI PERSEDIAAN BARANG PADA TOKO YOYO STATIONERY JAKARTA SELATAN
}

\author{
Fikrul Mustanir Fil Islam ${ }^{1}$, Dwi Yulistyanti ${ }^{2}$, Gita Kencanawaty ${ }^{3}$ \\ 1,2,3 Teknik Informatika, Fakultas Teknik dan Ilmu Komputer, Universitas Indraprasta PGRI \\ Jalan Raya Tengah No 80, Kelurahan Gedong, Pasar Rebo, Jakarta Timur \\ 1. fikruldanyong@gmail.com, 르indra.dwiyulist@gmail.com, ${ }^{3}$ gitakencanawaty@gmail.com
}

\begin{abstract}
ABSTRAK
Teknologi memberi kita kemudahan terutama dalam berkomunikasi dan dalam mendapatkan informasi. Kemajuan teknologi informasi ini juga bermanfaat dalam sistem informasi pada persediaan barang. Karena dalam sistem informasi pada persediaan barang akan sangat membantu sebuah instansi dalam mengelola persediaan barangnya. Toko Yoyo Stationery adalah toko yang ada di daerah Cilandak KKO yang menjual berbagai macam alat tulis. Tetapi sistem persediaan barangnya masih bersifat manual. Sehingga dalam pendataan, pencarian, dan pembuatan laporan data masih memerlukan waktu lama. Peneliti merumuskan masalah yaitu bagaimana merancang sistem persediaan barang, yang mana sistem tersebut dapat mengolah, mencari, dan membuat laporan secara cepat dan akurat, serta memudahkan dalam melakukan pencarian data. Tujuan penelitian ini membangun sistem informasi pada persediaan barang di Toko Yoyo Stationery yang telah terkomputerisasi, menggunakan bahasa pemrograman java dan database mysql. Agar pengolahan, pencarian, dan pembuatan laporan data yang tidak memerlukan waktu lama dan tidak ada lagi ketidaksesuaian dalam pengolahan dan pembuatan data laporan. Dalam proses penelitian, peneliti menggunakan metode R\&D (Research and development). Hasil penelitian ini adalah memperbaharui sistem informasi pada persediaan barang yang lama menjadi terkomputerisasi, sehingga mempermudah dalam pengolahan data sampai pembuatan laporan terkait persediaan barang di Toko Yoyo Stationery.
\end{abstract}

Kata Kunci: sistem informasi, persediaan barang, toko alat tulis, java

\begin{abstract}
Technology gives us convenience, especially in communicating and in obtaining information. Advances in information technology are also useful in inventory information systems. Because the inventory information system will really help an agency in managing its inventory. Yoyo Stationery Store is a store in the Cilandak KKO area that sells various kinds of stationery. But the inventory system is still manual. So that in data collection, searching, and making data reports it still takes a long time. The researcher formulates the problem, namely how to design an inventory system, where the system can process, search, and make reports quickly and accurately, and make it easier to search data. The purpose of this study is to build a computerized inventory information system at the Yoyo Stationery Store, using the Java programming language and mysql database. So that data processing, searching, and making data reports do not take long and there are no more discrepancies in processing and making report data. In the research process, the researcher uses the $R \& D$ (Research and development) method. The results of this study are to update the old inventory information system to be computerized, making it easier for data processing to making reports related to inventory at Yoyo Stationery Stores.
\end{abstract}

Key Word: information system, inventory, stationery store, java

\section{PENDAHULUAN}

Teknologi telah memberikan kemudahan bagi kita di dalam kehidupan ini, hampir setiap aspek kehidupan sudah memanfaatkan kecanggihan teknologi. Ada banyak fasilitas teknologi yang digunakan diantaranya untuk mempermudah komunikasi, memudahkan produktivitas kita sehari-hari, dan juga untuk mendapatkan informasi yang dibutuhkan. Informasi ini adalah sekumpulan data yang sudah diklasifikasikan atau diinterpretasi yang nanti akan digunakan untuk proses pengambilan keputusan. (Sutabri, 2012)

Kemajuan teknologi informasi juga meningkatkan sistem informasi pada persediaan barang. Persediaan barang yang berisi barang dagangan ini yang disimpan untuk dijual kembali oleh perusahaan dan ada juga barang yang masih tahap produksi yang disimpan untuk digunakan kedepannya. (Hermawan, 2013) 
Toko Yoyo Stationery adalah toko yang berada di daerah Cilandak KKO, yang menjual berbagai macam jenis alat tulis. Toko adalah tempat terjadinya aktivitas jual beli, yang biasanya menjual barang khusus seperti toko alat tulis. (Suprayitno \& Wardati, 2012)

Pada Toko Yoyo Stationery sudah memiliki sistem informasi pada persediaan barangnya tetapi masih bersifat manual. Sehingga ada beberapa masalah yang dihadapi oleh toko yaitu, dalam proses pengecekan data barang yang agak rumit, butuh waktu banyak saat mendata barang masuk dan barang keluar, terjadi selisih jumlah persediaan barang pada buku induk dengan di tempat penyimpanannya, tidak terdatanya informasi data barang secara lengkap, dan pendataan yang masih kurang akurat bagi toko.

Berdasarkan permasalahan diatas peneliti bermaksud untuk membangun sistem informasi pada persediaan barang menggunakan pemrograman Java Netbeans dengan database-nya $M y S Q L$ untuk mengatasi masalah tersebut.

Java ini adalah bahasa pemrograman untuk membangun halaman web dan dapat dijalankan untuk semua komputer. (Asropudin, 2013)

Sedangkan Netbeans merupakan sebuah aplikasi untuk membangun aplikasi dengan bahasa pemrograman Java. (Nofriadi, 2015)

MySQL adalah database yang biasanya digunakan untuk bahasa pemrograman PHP. Digunakan untuk menyimpan data dalam database sampai mengolah datanya. Seperti menambah, menghapus, mengedit dan lainlain. (Buana, 2014)

Hasil penelitian ini diharapkan dapat berguna bagi Toko Yoyo Stationery dalam pengolahan data persediaan barang pada tokonya secara cepat dan akurat, sehingga dapat meningkatkan kualitas kerja bagi Toko Yoyo Stationery.

\section{METODE PENELITIAN}

Tempat penelitian dilakukan pada salah satu toko yang menjual alat tulis kantor yaitu Toko Yoyo Stationery, terletak di Komplek Pertokoan Haji Madali, Jalan Raya Cilandak
Kko No.5, Kelurahan Ragunan, Kecamatan Pasar Minggu, Kota Jakarta Selatan.

Metode penelitian yang peneliti gunakan adalah metode $R \& D$ (Research and Development). Yang mana metode penelitian ini untuk menghasilkan produk yang lebih efektif dari sebelumnya. (Sugiyono, 2016)

Menggunakan metode $R \& D$ ini bertujuan untuk mengembangkan sebuah sistem yang ada melalui pengujian sehingga menghasilkan produk sistem yang lebih efektif.

Metode pengumpulan data yang digunakan peneliti sebagai berikut:

1. Studi Lapangan

Metode ini dilakukan peneliti secara langsung untuk mengumpulkan data dan keterangan yang diperlukan untuk membangun sistem informasi pada persediaan barang pada Toko Yoyo Stationery. Seperti wawancara, observasi, dan dokumentasi.

2. Studi Literatur

Pengumpulan data yang peneliti lakukan untuk merancang sistem informasi dengan cara membaca buku tentang bagaimana menganalisis, mendesain, dan merancang sistem. Serta membaca buku tentang bahasa pemrograman java dan database mysql.

Peneliti mengambil sumber rujukan dari jurnal Minarni dan Susanti dengan nomor eISSN/ISBN 1693-752X, pada tahun 2014 yang berjudul "Sistem Informasi Inventory Obat pada Rumah Sakit Umum Daerah (RSUD) Padang". Sistem inventory-nya masih bersifat manual. Dilakukan penelitian untuk menghasilkan program yang dapat mengontrol persediaan obat masuk dan keluar. (Minarni \& Susanti, 2014)

Selanjutnya peneliti juga mengambil sumber dari jurnal Hendra Agusvianto dengan nomor e-ISSN/ISBN 2549-869X, pada tahun 2017 yang berjudul "Sistem Informasi Inventori Gudang Untuk Mengontrol Persediaan Barang pada Gudang Studi Kasus: PT. Alaisys Sidoarjo". Pembuatan laporan dari gudang untuk ke kantor pusatnya diperlukan menyalin data dulu dari kartu ke microsoft office excel. Sistem tersebut menyebabkan pihak dari 
kantor pusat tidak bisa mengetahui data dari gudang secara efisien. Dilakukan penelitian untuk menghasilkan program aplikasi yang mana kantor pusat dapat mengetahui laporan dari gudang dengan tepat sasaran, akurat, dan efisien. (Agusvianto, 2017)

Peneliti dalam melakukan perancangan sistem informasi pada persediaan barang di Toko Yoyo Stationery adalah dengan menggunakan model waterfall. Metode waterfall adalah salah satu metode dalam merancang perangkat lunak secara terurut dimulai dari analisa, desain, coding, pengujian, dan pendukung (support). (Sukamto \& Shalahuddin, 2015)

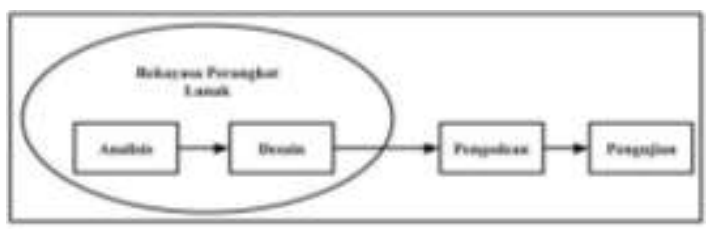

Gambar 1. Ilustrasi Model Waterfall

(Sumber: Rosa dan Shalahuddin, 2015)

Model waterfall ini terdapat beberapa tahapan pelaksanaan modelnya yaitu sebagai berikut:

1. Analisis Kebutuhan Perangkat Lunak Sebelum sistem buat, diperlukan suatu analis sebagai dasar untuk mengetahui kebutuhan sistem ke depannya. Analisis kebutuhan sistem terdiri dari analisis kebutuhan fungsional yang bertujuan untuk mengetahui kebutuhan fungsi sistem dan analisis kebutuhan non fungsional untuk mengetahui perangkat keras dan perangkat lunak yang dibutuhkan serta kriteria pengguna sistem.

2. Desain

Desain berfungsi sebagai dasar perancangan yang mengubah data-data yang didapat dari analisis menjadi sebuah rancangan yang terdiri dari desain struktur data, struktur navigasi, dan rancangan antar muka.

3. Pembuatan Kode Program

Tahapan ini merupakan lanjutan dari tahapan desain, yaitu mentranslasi desain menjadi sebuah program. Tahap ini menghasilkan suatu program yang sesuai dengan desain.
4. Pengujian

Program yang telah dibuat wajib diuji terlebih dahulu untuk memastikan bahwa program layak digunakan dari segi logic maupun fungsional. Pengujian ini dilakukan untuk meminimalisir kesalahan (error) dan memastikan keluaran yang dihasilkan sesuai dengan yang diinginkan.

5. Pendukung (Support) atau Pemeliharaan (Maintenance)

Program yang telah diuji dapat mengalami perubahan ketika sudah dikirimkan ke pengguna. Perubahan dapat terjadi karena terjadi kesalahan yang tidak terdeteksi saat pengujian program harus beradaptasi dengan lingkungan baru (hardware baru). Tahap pendukung atau pemeliharaan bertujuan untuk menjaga stabilitas program yang telah dibuat tanpa harus membuat program yang baru.

\section{HASIL DAN PEMBAHASAN}

Peneliti menggambarkan sistem dengan model DAD. DAD ini adalah sebuah diagram untuk menggambarkan aliran data yang masuk, proses aliran data, dan aliran data yang keluar. (Sukamto \& Shalahuddin, 2014)

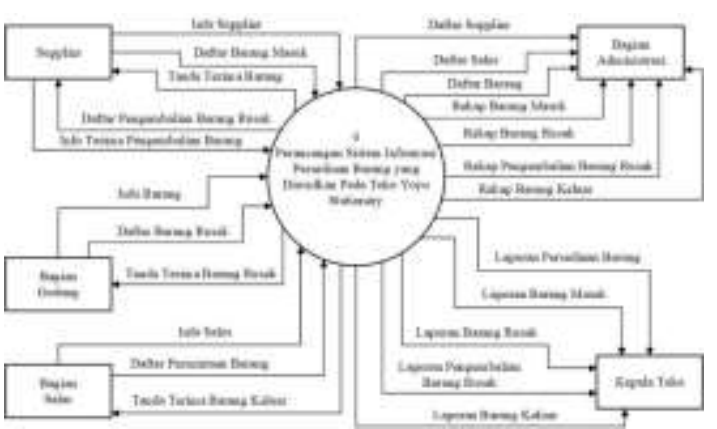

Gambar 2. Diagram Konteks yang Diusulkan 


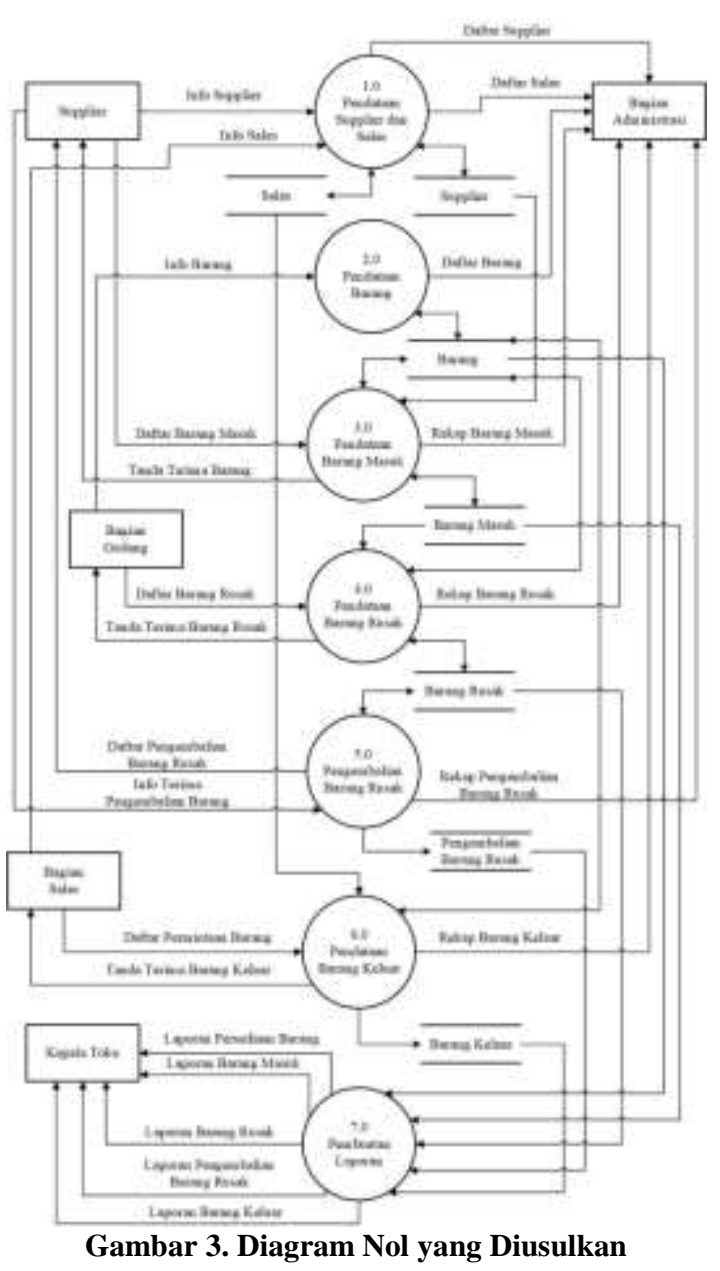

Aturan bisnis sistem yang diusulkan pada perancangan sistem informasi pada persediaan barang di Toko Yoyo Stationery adalah sebagai berikut:

1. Proses Pendataan Supplier dan Sales

a. Supplier yang mengirim barang ke toko memberikan data-data terkait supplier tersebut ke bagian administrasi.

b. Bagian administrasi menginput data-data supplier tersebut ke dalam sistem database.

c. Bagian administrasi menginput data-data sales pada toko ke dalam sistem database.

2. Proses Pendataan Barang

a. Bagian gudang memberikan data barang pada gudang ke bagian administrasi.

b. Bagian administrasi menginput data barang ke dalam sistem database.

3. Proses Pendataan Barang Masuk

a. Supplier mengirim barang ke toko diterima oleh bagian gudang. b. Supplier memberikan daftar barang masuk ke bagian administrasi, lalu supplier menerima tanda terima barang.

c. Bagian administrasi menginput data barang masuk ke dalam sistem database.

4. Proses Pendataan Barang Rusak

a. Bagian gudang memberikan daftar barang rusak ke bagian administrasi.

b. Bagian gudang menerima tanda terima barang rusak dari bagian administrasi.

c. Bagian administrasi menginput data barang rusak ke dalam sistem database.

5. Proses Pengembalian Barang Rusak

a. Bagian administrasi memberikan daftar pengembalian barang rusak ke supplier.

b. Supplier memberikan tanda terima pengembalian barang ke bagian administrasi.

c. Bagian administrasi menginput data pengembalian barang rusak ke dalam sistem database.

6. Proses Pendataan Barang Keluar

a. Bagian administrasi menerima daftar permintaan barang dari sales untuk pengisian display pada toko.

b. Bagian sales menerima tanda terima barang keluar dari bagian administrasi.

c. Bagian administrasi menginput data barang keluar ke dalam sistem database.

7. Proses Pembuatan Laporan

a. Setiap minggu bagian administrasi mencetak laporan persediaan barang, laporan barang masuk, dan laporan barang keluar dari sistem database.

b. Bagian administrasi menyerahkan laporan persediaan barang, laporan barang masuk, dan laporan barang keluar ke kepala toko.

Peneliti menggambarkan database dengan model ERD. Yaitu pembuatan model basis data yang dikembangkan sesuai teori himpunan di dalam matematika untuk pembuatan model basis data yang relasional. (Sukamto \& Shalahuddin, 2014) 


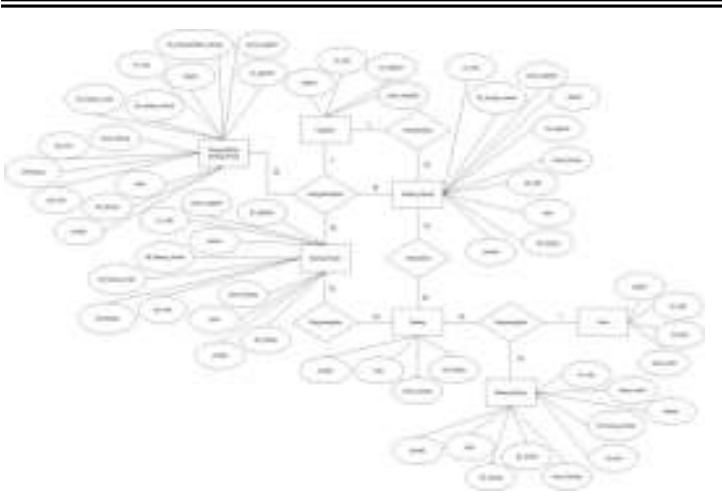

Gambar 4. ERD (Entity Relationship Diagram)

Peneliti merancang tampilan aplikasi ini dengan menggunakan aplikasi netbeans 8.2. Berikut tampilan dari aplikasi inventori Toko Yoyo Stationery:

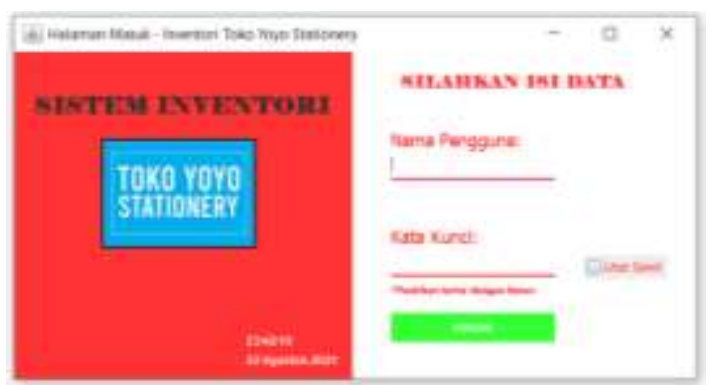

Gambar 5. Tampilan Halaman Masuk

Tampilan layar halaman masuk untuk masuk ke menu utama, yang mana pengguna harus mengisi data nama pengguna serta kata sandi sesuai database.

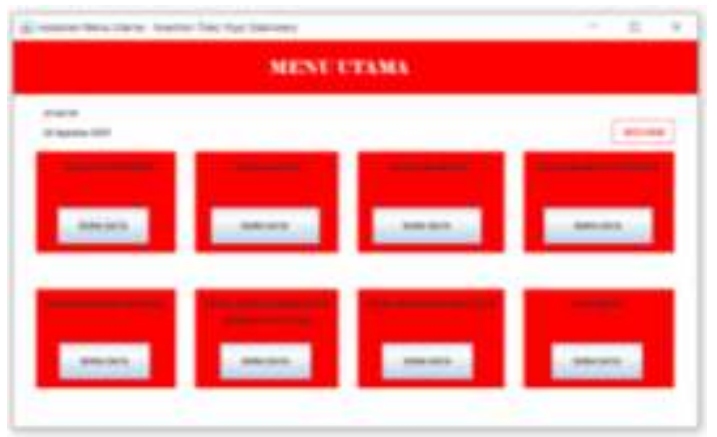

Gambar 6. Tampilan Halaman Menu Utama

1. Pada menu utama, di panel data supplier berfungsi untuk mengolah terkait data supplier.

2. Pada menu utama, di panel data sales berfungsi untuk mengolah terkait data sales.

3. Pada menu utama, di panel data barang berfungsi untuk mengolah terkait data barang.
4. Pada menu utama, di panel data barang masuk berfungsi untuk mengolah terkait data barang masuk.

5. Pada menu utama, di panel data barang rusak berfungsi untuk mengolah terkait data barang rusak.

6. Pada menu utama, di panel data pengembalian barang rusak berfungsi untuk mengolah terkait data pengembalian barang rusak.

7. Pada menu utama, di panel data barang keluar berfungsi untuk mengolah terkait data barang keluar.

8. Pada menu utama, di panel laporan berfungsi untuk mencetak seluruh laporan pada inventori Toko Yoyo Stationery.

\section{SIMPULAN DAN SARAN}

Kesimpulan dari perancangan sistem informasi pada persediaan barang di Toko Yoyo Stationery ini antara lain:

Dengan adanya aplikasi inventori ini pengolahan data barang, barang masuk, barang keluar, barang rusak, dan pengembalian barang rusak sudah terkomputerisasi. Dengan adanya aplikasi inventori yang sudah terkomputerisasi ini, dalam pencarian data tidak memerlukan waktu lama.

Dengan adanya aplikasi inventori ini proses pencatatan data dan penyimpanan data sudah menjadi lebih baik. Dengan adanya aplikasi inventori ini dalam pembuatan laporan dapat dilakukan dengan mudah karena sudah dapat dicetak secara otomatis.

Agar aplikasi inventori ini lebih optimal dan berjalan sesuai dengan harapan, maka peneliti memberikan sesuatu yang dapat diajukan dan dapat dijadikan bahan pertimbangan untuk pengembang atau peneliti lain yaitu:

Sebaiknya untuk kedepannya dilakukan penambahan sistem grafik barang yang sering dibeli oleh customer. Membuat sistem keamanan yang lebih baik untuk pengembangan selanjutnya sesuai kebutuhan perusahaan di masa mendatang. Perlu dikembangkan kualitas tampilan pada sistem yang lebih baik demi kenyamanan dan keefektifan penggunaan oleh $u s e r$. 


\section{UCAPAN TERIMAKASIH}

Terima kasih kepada Bapak H. Buchari selaku Kepala Toko Yoyo Stationery yang telah memberi izin penelitian di Toko Yoyo Stationery.

\section{DAFTAR PUSTAKA}

Agusvianto, H. (2017). Sistem informasi inventori gudang untuk mengontrol persediaan barang pada gudang studi kasus : PT.Alaisys Sidoarjo. Journal Information Engineering and Educational Technology, 01(01), 4046.

Asropudin. (2013). Kamus teknologi informasi komunikasi. Bandung: CV Titian Ilmu.

Buana, I. K. (2014). Jago pemrograman PHP. Jakarta: Dunia Komputer.

Hermawan, S. (2013). Akuntansi perusahaan manufaktur. Yogyakarta: Graha Ilmu.

Minarni, \& Susanti. (2014). Sistem informasi inventory obat pada Rumah Sakit Umum Daerah (RSUD) Padang. Jurnal Momentum, 16(1), 103-111.

Nofriadi. (2015). Java fundamental dengan netbeans 8.0.2. Yogyakarta: DeePublish.

Sugiyono. (2016). Metode penelitian kuantitatif, kualitatif dan $R \& D$. Bandung: Alfabeta.

Sukamto, R. A., \& Shalahuddin, M. (2014). Rekayasa perangkat lunak : Terstruktur dan berorientasi objek. Bandung: Informatika.

Sukamto, R. A., \& Shalahuddin, M. (2015). Rekayasa perangkat lunak : Terstruktur dan berorientasi objek. Bandung: Informatika.

Suprayitno, \& Wardati, U. I. (2012). Pembangunan sistem stok barang dan penjualan pada Toko Sero Elektronik. Journal Speed, 4(4), 8-16.

Sutabri, T. (2012). Konsep sistem informasi. Yogyakarta: Andi. 